Estuaries and coasts : Journal of the Estuarine Research Federation

November 2014, Volume 37 Issue 6 Pages 1319-1328

http://dx.doi.org/10.1007/s12237-013-9641-0

http://archimer.ifremer.fr/doc/00171/28218/

(c) Coastal and Estuarine Research Federation 2013

\title{
Observations on the Lateral Structure of Wind-Driven Flows in a Stratified, Semiarid Bay of the Gulf of California
}

\author{
Winant Chloe ${ }^{1}$, Valle-Livinson Arnoldo ${ }^{1, *}$, Ponte Aurelien ${ }^{2}$, Winant Clinton ${ }^{3}$, \\ Gutierrez-De-Velasco Guillermo ${ }^{4}$, Winters Kraig ${ }^{3}$ \\ ${ }^{1}$ University of Florida, Civil and Coastal Engineering, Gainesville, FL, USA \\ 2 IFREMER, Laboratoire de Physique des Océans, Centre Bretagne,Plouzané, France \\ * Corresponding author : Arnoldo Valle-Livinson, email address : arnoldo@ufl.edu
}

${ }^{3}$ Scripps Institution of Oceanography, La Jolla, CA, USA

${ }^{4}$ CICESE, La Paz, México

\begin{abstract}
:
Time series of current velocity profiles and thermistor chains were obtained throughout a cross-bay transect for $\sim 90$ days for the purpose of comparing observed wind-driven stratified flows to theory. This study concentrates on the synoptic scale wind and its influence on the bay's circulation. The maximum water column stratification was $3-4{ }^{\circ} \mathrm{C} / \mathrm{m}$ throughout the deployment and influenced wind-driven flows. Low-pass filtered flows showed more complicated structures than those expected from theory: a depthdependent recirculating structure with the along-bay flow over one half of the transect moving in opposite direction to the other half. Analysis of complex empirical orthogonal functions indicated that the first six modes explained $80 \%$ of the flow variability. Therefore, there was no predominantly energetic mode of variability. All modes exhibited a rich spatial structure with vertical and lateral variations. For all modes there was vertically sheared bidirectional flow, as expected from theory, with the largest eigenvector (mode value) asymmetrically influenced by Earth's rotation and advection of momentum.
\end{abstract}

Keywords : Wind-driven flow, Stratification, Concepcion Bay, . Semiarid 


\section{Introduction}

Numerical and analytical results of wind-driven flow in a homogeneous semienclosed basin with lateral variations in bathymetry indicate a circulation structure that consists of downwind flow over shallow areas and upwind flow in the deepest part of the cross-section (e.g. Csanady, 1973; Mathieu et al., 2002; Winant, 2004; Sanay and Valle-Levinson, 2005). Observations in a Gulf of California bay (Northern Hemisphere) during practically unstratified conditions showed, however, a different structure (Ponte et al., 2012). Downwind flow appeared occupying the entire water column on the right, relative to the wind direction, and upwind flow developed over the left portion of the cross-section. Differences between theoretical results and observations were attributed mainly to two factors: a) influence of advective accelerations and b) effects of lateral shear in wind stress (wind stress curl). The lack of a well-defined channel flanked by distinct shoals can also be a reason for the discrepancy. Advective accelerations and wind stress curl have not been considered in previous analytical solutions and both seem to favor the wind-driven flow structure observed during the unstratified season. Nevertheless, the results of Sanay and Valle-Levinson (2005) did include effects of advective accelerations and still showed the response of downwind flow over shoals and upwind flow in the channel.

It has been shown that the wind-driven circulation pattern can be modified from laterally sheared to vertically sheared by the shape of the bathymetry (Valle-Levinson, 2011). Over relatively flat cross-sections with no well-defined channel, the wind-driven exchange flow is vertically sheared with downwind flow at the surface and upwind flow underneath. In contrast, over a cross-section with well-defined shoals and channel, the flow is downwind over shoals and upwind in the channel. However, little observational evidence exists about the response of stratified flows to wind forcing in a semienclosed system. Numerical model results show marked influences from stratification on wind-driven flows, relative to homogeneous conditions, as frictional effects decrease throughout the water column (e.g. Guo and Valle-Levinson, 2008; Chen and Sanford, 2009). The purpose of this study is to explore with observations the subinertial flow patterns in a stratified bay of the Gulf of California, Bahia Concepcion. This bay is located near an amphidromic point for semidiurnal tides, thus minimizing the effects of semidiurnal tidal forcing.

\section{Study Area}

Bahia Concepcion, or Concepcion Bay, is located close to the middle of the Gulf of California side of the Baja California peninsula in Mexico (Fig.1). The bay is centered at $111.83^{\circ} \mathrm{W}$ and $26.72^{\circ} \mathrm{N}$, is $\sim 40 \mathrm{~km}$ long, $\sim 7 \mathrm{~km}$ wide and $20 \mathrm{~m}$ deep on average. The bay can be subdivided in two portions, with approximately the same length, according to its orientation. The northern portion is oriented roughly in the north-south direction, although its coastline and bathymetry exhibit an eastward curvature. In this portion of the bay the bathymetry roughly parallels the coastline with a $\sim 30 \mathrm{~m}$ channel incising the bottom, but interrupted by a $\sim 15 \mathrm{~m}$ sill near the bay entrance. The southern portion features a southeast-northwest orientation with a bowl-like bathymetry of typically $25 \mathrm{~m}$ depths.

The climate in the bay area is semiarid characterized by winter rains associated with cold fronts from the north. Winter is also characterized by relatively strong $(\sim 10 \mathrm{~m} / \mathrm{s})$ northwesterly winds (Cheng et al., 2010; Ponte et al., 2012) that maintain well mixed conditions in the bay's water column. Summer months bring southerly winds to the bay and intense heating causes well developed stratification with temperature contrasts between surface and bottom of up to $10^{\circ} \mathrm{C}$ (Cheng et al., 2010). Summer weather systems that affect the Eastern Tropical Pacific occasionally make their way to the latitude of the bay and dump 
pulses of rain of 1-2 $\mathrm{cm}$ over 1-2 days. Typical wave periods at the bay entrance are between 3 and $5 \mathrm{~s}$ and become $3 \mathrm{~s}$ at the head. Long-period swell waves are dissipated mainly by the change of bay orientation (Caliskan and Valle-Levinson, 2008).

Tides at the bay entrance are mixed with diurnal dominance as the ratio of diurnal to semidiurnal tidal constituents is 2.4 (Ponte et al., 2012). Semidiurnal constituents are suppressed at this location by an amphidromic point of those frequencies (Morales and Gutiérrez de Velasco, 1989; and Hendershott and Speranza, 1971). Tidal ranges can reach $1.25 \mathrm{~m}$ at spring tides and are $<0.5 \mathrm{~m}$ at neap tides, dominated by diurnal constituents. Tidal currents at the bay entrance are typically $<0.2 \mathrm{~m} / \mathrm{s}$ and remain relatively weak throughout. Tidal waves in the bay are near-standing as currents lead water elevation by nearly $90^{\circ}$ (Ponte et al., 2012). The inertial period in the area is close to $27 \mathrm{~h}$. The relatively weak influence of semidiurnal tides on the bay allowed examination of wind forcing effects on circulation at subinertial periods.

\section{Methods}

Observations of current velocity profiles and discrete temperature time series were recorded at a cross-bay transect during the period of strongest water column stratification of the year (Cheng et al., 2010), from July to October 2005. The bathymetry of the 6-km observation transect (Fig. 1) featured an asymmetric U-shaped distribution with maximum depth of $30 \mathrm{~m}$ shifted to the left (looking seaward) from the middle. Measurements concentrated in the southern portion of the bay, where the bathymetry is least complicated. Velocity profiles were obtained with 7 bottom-mounted RD Instruments acoustic Doppler current profilers (ADCPs) that recorded 150 pings averaged over 10-minute ensembles with a vertical resolution of $1 \mathrm{~m}$. Of the 7 ADCPs, 4 operated at a frequency of $1228.8 \mathrm{kHz}$ and were deployed at depths of $15,16,19.5$ and $23.5 \mathrm{~m}$. The remaining 3 functioned at $614.4 \mathrm{kHz}$ and were positioned at $25.7,26.5$ and $26.75 \mathrm{~m}$ depths. All velocity values had a measurement standard deviation $<0.3 \mathrm{~cm} / \mathrm{s}$. Six thermistor chains were deployed within $200 \mathrm{~m}$ of each ADCP except for the central mooring at $26.75 \mathrm{~m}$. Thermistors recorded at periods of 4 minutes and were distributed along each chain at intervals of $5 \mathrm{~m}$ below the surface. The thermistors used have an accuracy of $0.018^{\circ} \mathrm{C}$ and were manufactured at the Hydraulics Laboratory of the Scripps Institution of Oceanography. Moreover, in order to determine water level slopes inside the bay, two SeaBird Conductivity-Temperature recorders Model SBE26 with Paroscientific pressure sensors were deployed over depths of $\sim 5 \mathrm{~m}$ at the mouth and head of the bay (white squares in Fig.1). Within $200 \mathrm{~m}$ of both bottom pressure recording locations, meteorological stations measured wind speed and direction that were used to characterize wind stresses according to Large and Pond (1981).

In this study, high frequency (periods $<40 \mathrm{~h}$ ) variability was filtered out with a Lanczos filter to study subinertial variations of exchange flows under stratified conditions. Moreover, in order to synthesize nearly 3 months of velocity profiles at 7 locations, an analysis of Complex Empirical Orthogonal Functions (CEOFs, Emery and Thomson 2001) was carried out with the records. For each ADCP bin, subinertial current velocities were included as one observation point in the form of a complex variable $u+i v$, where $u$ and $v$ are the subinertial east and north components of velocity, respectively, and $i$ is the imaginary number $(-1)^{1 / 2}$. The CEOF analysis consists of solving the eigenvalue problem related to the covariance matrix of all data (7 complex velocity profiles varying in time). Resulting eigenvectors allowed identification of the dominant structure of flow profiles at all stations, simultaneously. Temporal fluctuations of eigenvectors described the variability of all profiles, the real part for $u$ and the imaginary part for $v$. Descriptions of temporal variations of eigenvector coefficients concentrated in the along-bay component $u$ as the standard deviation of the variations for $u$ 
were 3 to 5 times larger than those for $v$ in Modes 1 and 2. Because this is a statistical approach to separate a set of time series in different modes of variability, it is sometimes challenging to find a physical connection between the statistical CEOF modes and a causative influence. In this study, at least the most relevant modes were related to a causative effect as presented in the results.

\section{Results}

The main driving forces in the bay during the period of observation were the wind and the diurnal tides. Winds were predominantly from the south, with well-defined diurnal (seabreeze) and synoptic (2-7 days) temporal variability. Sea-breezes and diurnal tides were filtered out from the record to concentrate on the subinertial variability in the bay. Subinertial water level slopes inside the bay $(\partial \eta / \partial y)$ responded closely to the accelerations produced by the north component of the subinertial wind stress $\left(\tau_{y} /(\rho g H)\right.$, where $\rho$ is the density of seawater, $g$ is the acceleration caused by gravity, and $H$ is water depth, Fig. 2a). During fall and winter unstratified conditions, the correlation between $\partial \eta / \partial y$ and $\tau_{y} /(\rho g H)$ was 0.85 with a regression slope of 0.97 (Ponte et al., 2012). In contrast, during the stratified period reported here, the correlation between slope and wind stress was 0.62 with a regression slope of 0.73 . Decreased correlation was expected during stratified conditions as the one-toone relationship between $\partial \eta / \partial y$ and $\tau_{y} /(\rho g H)$ does not consider variations in water density, which were substantial as described next with water temperature measurements.

Stratification conditions in the bay were described with data from one of the thermistor chains. Time series of temperature profiles in the middle of the transect showed a stratified water column in which typical surface-to-bottom differences were $10^{\circ} \mathrm{C}$ in $20 \mathrm{~m}$ depth (Fig. $2 b)$. Heat content clearly increased throughout the water column from the beginning to the end of the deployment (Cheng et al., 2010). As pointed out by these authors, most of the heat content change was attributed to atmospheric heat fluxes. However, the largest changes during the first month were caused by transport of upwelled waters from outside the bay mouth. Maximum water column stratification was close to $4{ }^{\circ} \mathrm{C} / \mathrm{m}$ in the middle of the deployment (days 234-235, Fig. 2c), coinciding with a surface increase and bottom decrease in temperature. The thermocline, which likely coincided with the pycnocline and was denoted by the darkest blue shades in Figure 2c, migrated downward from a depth of $\sim 10 \mathrm{~m}$ at the beginning of the deployment in July to a depth close to $20 \mathrm{~m}$ after day 235 (August $23^{\text {rd }}$ ). The thermocline deepening was associated with atmospheric heating from July to September.

Anomalies in stratification strength were calculated as the difference between the time series of maximum stratification in the water column and a 10-day running mean of the same signal of maximum stratification (Fig. 2d). Oscillations of such anomaly showed largest positive values on days 207 and 234, indicating the greatest stratification of the observation period. Most negative anomalies occurred on days 204 and 236, which were associated with minimum stratification conditions. The anomalies portrayed in Figure $2 \mathrm{~d}$ could be regarded as thermocline oscillations and were remarkably linked to temporal variations in water level slope along the bay, but with the opposite sign. Greatest stratification on days 207 and 234 appeared after northward winds, during the transition from positive water slopes to negative slopes inside the bay. Upwelled, relatively cooler, waters outside the bay (from northward winds) were advected into the bay after wind and water level slope relaxation and contributed to such an increase in stratification (e.g. Cheng et al. 2010). Pycnocline oscillations, represented by the anomalies of Figure $2 \mathrm{~d}$, displayed a maximum spectral peak (not shown) 
at a period of $\sim 13.5$ days associated with the beating of the two tidal diurnal constituents $\left(\mathrm{O}_{1}\right.$ and $\left.\mathrm{K}_{1}\right)$ or the interaction between the diurnal sea breeze and the diurnal tide $\left(\mathrm{O}_{1}\right)$. Pycnocline oscillations also showed prominent spectral peaks at periods of 5 days related to wind forcing and to fluctuations in low-pass filtered flow. Figure $2 \mathrm{~d}$ suggests that pycnocline oscillations during the observation period were caused by wind-driven set-up and set-down, i.e., mostly by advective rather than diffusive effects.

Low-pass filtered flows (Fig. 3) showed more complicated structures than those expected from linear theory (e.g. Winant, 2004; Sanay and Valle-Levinson, 2005). At a bay crosssection, linear theory predicts downwind flow over the relatively shallow sides of the bay and upwind flow in the deepest portion of the middle. Or, perhaps, because the bay's crosstransect variations in bathymetry are relatively weak, linear theory would predict downwind flow at the surface with upwind flow underneath. Observations frequently showed portions of the cross-section, e.g. the western half, displaying flows in one direction while at the other portion, water flowed in the opposite direction (e.g. day 278, Fig. 3). In general, there was consistency in the flow structure among the westernmost 3 sites and between 2 of the 3 easternmost. The easternmost site was different from the rest because of a broad headland in the vicinity of the measurements, which should be modifying the flows locally. Also, flows appeared vertically sheared over some of the sampling sites but they were vertically uniform or sheared in the opposite direction at other sites (e.g. day 195 or 210). These flows showed no clear or obvious relationship to wind forcing, except for some instances such as between days 225 and 240 on the westernmost portion of the bay where downwind flow developed at the surface and upwind flow appeared near the bottom. In general, wind forcing was rather weak (uppermost panel of Fig. 3), with low-pass filtered wind velocities being consistently lower than $2 \mathrm{~m} / \mathrm{s}$. This relatively weak forcing was likely the reason for a lack of immediately discernible flow structures. Flow variability at the transect sampled was visibly rich in space and time. But distinguishing distinct responses of the flow to subinertial forcing was not obvious from Figure 3.

In order to investigate distinct modes of variability of subinertial flows, low pass-filtered velocity records were decomposed in complex empirical orthogonal functions (CEOFs). Mean flows (Fig. 4) were subtracted before implementing the CEOF analysis. Mean flows showed a depth-dependent recirculating structure with the flow over the western half of the transect (left on Fig. 4) moving into the bay at maximum mean speeds of $3.5 \mathrm{~cm} / \mathrm{s}$ centered at $13 \mathrm{~m}$ depth. Flow in the opposite direction developed in the eastern half (right half looking seaward), occupying a greater area of the cross-section than the inflowing portion but with weaker speeds of $<2 \mathrm{~cm} / \mathrm{s}$ and centered at $\sim 18 \mathrm{~m}$. Lateral flows depicted eastward (from left to right) motions associated with a mean cyclonic recirculation. Near the surface, the flow moved seaward with the deployment-mean wind. The structure of mean flows during this stratified season was comparable but weaker, at least below 8-10 m depth, to that observed during unstratified conditions (Ponte et al., 2012). The distinct feature between unstratified and stratified water column was the downwind flowing upper-most part of the water column (above $\sim 8 \mathrm{~m}$ ). The cyclonic recirculation observed throughout the water column during unstratified conditions was attributed to advective accelerations and lateral shears of wind stress (Ponte et al., 2012), and also to wave stresses (Winant, 2011). Persistence of such recirculation during stratified conditions, albeit below a surface layer $\sim 8 \mathrm{~m}$ thick, suggests that advective accelerations caused by diurnal (tidal or sea breeze forcing) forcing were likely most influential in the recirculation development. Deviations from the mean flow structure during stratified conditions were determined by the spatial and temporal structures of the CEOFs. 
Results of the CEOF analysis indicated that there was predominance, although rather weak, of two modes (Fig. 5). Each of these two modes explained $\sim 33 \%$ and $20 \%$ of the total variability of the signal. The first 6 modes combined explained $80 \%$ of the subinertial flow variability during stratified conditions. This was in contrast to $92 \%$ explained by 3 modes during unstratified conditions, with mode 1 accounting for $\sim 82 \%$ (Ponte el al., 2012). Wind forcing was typically twice as strong during unstratified conditions and was responsible for most of the subinertial flow variability in that period. As mentioned, forcing during stratified conditions was markedly weaker and was likely the reason for the CEOF analysis not extracting a greatly dominant mode. Indeed, every mode related to stratified conditions exhibited an intricate spatial structure with vertical and lateral variations (Fig. 5). Mode 1 showed an exchange structure for the along-bay flow that was vertically sheared within the transect portion between the western shore and $4 \mathrm{~km}$ to the East. Between 4 and $6 \mathrm{~km}$, the exchange flow was also vertically sheared but in the opposite direction and markedly weaker than on the western part of the bay. Positive values in Figure 5 (white-shaded contours) indicated flows toward the mouth of the bay whenever Mode 1 coefficients (the real part), shown in Figure 6, were positive. Thus, two major pulses of vertically sheared flow consisting of surface flow out of the bay and bottom flow into the bay were centered on days 205 , lasting $\sim 3$ days, and day 230 , lasting $\sim 5$ days. These two pulses could be identified by looking back at Figure 3 and detecting positive contours at the surface of the westernmost stations. Positive values of the temporally varying coefficients (Fig. 6, Mode 1) were associated with northward water level slopes from head to mouth of the bay and northward winds (Fig. 3). Similarly, two negative pulses, indicating near-surface inflow and near-bottom outflow, were centered on days 200, 210 and 240 (see also Fig. 3). These were associated with negative surface slopes inside the bay, caused by southward winds (top panel of Fig. 3). As seen by the spectral energy associated with Mode 1 coefficients (Fig. 6), there was no predominant periodicity and most of the variability was distributed in frequencies lower than 0.07 cycles per day, i.e., periods greater than 14 days.

The spatial structure of Mode 2 showed a laterally sheared flow structure (Fig. 5) that was toward the head (negative) over the western portion of the transect and seaward over the eastern part. Positive coefficients of Mode 2 (Fig. 6) indicated a cyclonic recirculation, such as the pulses centered on days 238 and 250. Flow structures observed during periods of positive Mode 2 coefficients were consistent with the cyclonic gyre structure observed in the unstratified season (Ponte et al., 2012). The pulse of day 238 in Mode 2 coincided with a relatively large negative pulse of Mode 1 . Therefore, both modes (associated with vertically and laterally sheared flows) contributed to the subinertial circulation during that period (Fig. 3 ). The pulse of day 250 was not accompanied by another pulse from other modes and therefore was clearly apparent, although short-lived, in the subinertial flow. On the other hand, anticyclonic circulation in the bay would be expected when Mode 2 coefficients were most negative, as between days 200 and 205 (white-shaded contours throughout the water column at westernmost sites 1 and 2, and dark-shaded contours throughout the water column at sites 5 and 6, Fig. 3), on day 242 (large pulse of Mode 1 at this time also, though) and on day 272 (clearly observed on Fig. 3). Mode 2 was related to the lateral shear throughout the transect as calculated from the difference between the extreme subinertial flows at each end of the transect. This mode was an indication of the preference of laterally sheared volume exchange over vertically sheared exchange. The spectral energy of Mode 2 coefficients was dominated by $\sim 10$ day variability $(\sim 0.1$ cycles per day) likely forced by variability in the adjacent Gulf of California.

Also related to remote forcing from the gulf was the spatial structure and temporal variability of Mode 3. This mode was negative (into the bay) practically throughout the transect (Fig. 5) with weak positive values near bottom. Greatest positive values of Mode 3 coefficients were centered on days 211, 247 and 203 (Fig. 6) but were combined with other, more energetic 
modes. The same could be said about the largest negative coefficients, which were masked by either Mode 1 or 2 . Therefore, net inflow into or outflow from the bay was not readily observed at all sites simultaneously (Fig. 3). Nonetheless, Mode 3 was related to the sectionally averaged flow (Fig. 6), which represented net transport, albeit weak, into or out of the bay. The dominant periodicity of Mode 3 was related to frequencies $<0.03 \mathrm{cpd}$ or periods $>1$ month as given by the spectral peak of its coefficients. There was also a spectral peak at $0.11 \mathrm{cpd}$, equivalent to periodicities of 8.6 days, and likely related to remote forcing from the Gulf of California.

Mode 4 was markedly sheared in the vertical throughout the transect (Fig. 4). Real positive values of its coefficients indicated inflow at the surface and outflow underneath, typical of inverse estuarine circulation. Two instances when this should have happened were on days 234 and 274 (Fig. 6). Vertically sheared exchange flows on day 234 actually combined with negative values of Mode 1 , for strongly vertically sheared flow on the western part of the transect (sites 1, 2 and 3) that featured net surface inflow and net bottom outflow (Fig. 3). On day 274 a flow structure emulating inverse estuarine circulation was observed. On the other hand, negative values of Mode 4 would indicate typical estuarine-like circulation, i.e., outflow at surface and inflow underneath, and were only salient on day 249 , which combined with positive values of Mode 2. This resulted in an amalgamation of vertically sheared and horizontally sheared exchange flows. The time-varying coefficients for Mode 4 were highly correlated to the top-to-bottom velocity differences in the middle of the bay (Fig. 6). Mode 4 coefficients showed a spectral peak around 0.125 cycles per day or 8-day period, similar to the periodicity of Mode 3 , but in this case there was no dominance of lower frequencies.

Modes 5 and 6 exhibited 3-layered structures that changed from one side of the crosssection to the other (Fig. 5). This structure was apparent on day 235, as indicated by the most negative coefficient of Mode 5 (Fig. 6) and by the observed subinertial flow: inflow at surface and bottom with outflow in between, at the central sites of the transect (sites 3, 4, 5, and 6). It seems that the transition between northward and southward winds, which caused the largest change from positive to negative slopes in water elevation of the observation period, allowed development of 3-layered exchange flows. Mode 5 was influenced by frequencies $<0.05 \mathrm{cpd}$ (periods greater than 20 days) and $0.15 \mathrm{cpd}$ (periods around oneweek), even though it was only apparent once during the entire record. Mode 6 was influenced by low frequencies and seems to have been related to a month-long trend of the coefficients that was actually masked in the observations by more energetic and frequent pulses.

\section{Discussion}

For all CEOF modes the eigenvectors showed vertically sheared bidirectional flow, at least in some portion of the cross-section (Fig. 5). Bidirectional flow in the vertical plane is expected from theory of wind-driven (e.g. Csanady, 1973) and tidal residual (e.g. lanniello, 1977) flow over flat bottom depths equivalent to those in the middle of the bay. Also for all CEOF modes, the largest eigenvector values were asymmetrically distributed at the cross-section, i.e., did not appear in the middle of the cross-section as would be expected from open channel flow (e.g. Henderson, 1966). This asymmetry could have been caused by spatial variability of the forcing (wind curl), by advective accelerations, or by water column stratification (Ponte et al., 2012). It could also have been driven by Earth's rotation, or by wave stresses (Winant, 2011). Scaling the advective acceleration term $\left\langle u^{\prime} \partial v^{\prime} \mid \partial x\right\rangle$, where brackets denote subinertial averaging, with typical superinertial transverse shears of along 
bay flow $\partial v^{\prime} / \partial x$ and superinertial cross-bay flows $u^{\prime}$ yields values between 1 and $5 \times 10^{-6} \mathrm{~m} / \mathrm{s}^{2}$. In turn, scaling Coriolis accelerations $f u$ with $f$ of $6.5 \times 10^{-5} \mathrm{~s}^{-1}$ produces values between $7 \times 10^{-7}$ and $3 \times 10^{-6} \mathrm{~m} / \mathrm{s}^{2}$. Scaling suggests that both Coriolis and advective accelerations, could have contributed to the dominant exchange flow modes observed. It seems that wind stress was sufficiently weak $\left(<0.005 \mathrm{~Pa}\right.$, causing accelerations of order $\left.10^{-8} \mathrm{~m} / \mathrm{s}^{2}\right)$ during most of the observation period to have influenced the flow through wind curl or wave stresses.

Asymmetries in the eigenvector distributions throughout the bay's cross-section showed the strongest Mode 1 flows appearing on the western portion of the bay, where the flow was essentially two-layered: downwind at the surface and return flow underneath. Advective accelerations that shaped these flows could have been related to the coastal morphology and bathymetry that caused wind and flow acceleration around the curving coastline and bathymetry (see Fig. 1). Interestingly, the spatial structure of Mode 1 was also laterally sheared at the surface, within the uppermost $10 \mathrm{~m}$. Recirculation above the pycnocline was likely associated with this distribution. Another interesting feature of the spatial structure of Mode 1 was the near-bottom positive portion over the eastern side of the bay, below $20 \mathrm{~m}$ and east of $3.5 \mathrm{~km}$ (Fig. 5, Mode 1). It is possible that this near-bottom flow was caused by hypersaline and inverse longitudinal density gradient conditions in the bay, driving nearbottom outflow. Obviously, this could only happen during the times of positive values of the temporally varying coefficients (Fig. 6). Density-driven flows should have magnitudes of (Officer, 1976) $g G H^{3} /\left(48 \rho A_{z}\right.$ ), where $g$ is gravity's acceleration, $G$ is a horizontal density gradient, $H$ is water column depth, $\rho$ is a reference water density, and $A_{z}$ is a vertical eddy viscosity. For $H$ of $25 \mathrm{~m}$ in Concepcion Bay, taking $A_{z}$ of $1 \times 10^{-4}$ to $1 \times 10^{-3} \mathrm{~m}^{2} / \mathrm{s}$, would require a $G$ of between $1 \times 10^{-6} \mathrm{~kg} / \mathrm{m}^{4}$ and $1 \times 10^{-5} \mathrm{~kg} / \mathrm{m}^{4}$ for a density-driven flow of $\sim 0.05 \mathrm{~m} / \mathrm{s}$. Values of $G$ of these orders of magnitude, albeit in the cross-bay direction, were observed in the bay during that time of year (Cheng et al., 2010). Therefore, it is possible that density-driven flows could have complicated the picture further. There is no convincing way of showing this without measurements of along-bay density gradients.

Flow structures in Concepcion Bay during stratified conditions, typically between March and October, were much less defined and more variable than during unstratified conditions (November through January). In the latter period, the dominant flow structure responded clearly to wind forcing and displayed a cyclonic recirculation in the southern half of the bay (Ponte et al., 2012). Advective accelerations and spatial variations in wind forcing (wind curl) were responsible for the cyclonic character of the recirculation. This recirculation differed from theoretical structures of downwind flow at surface and return flow underneath, or a double gyre shaped by downwind flows over shallow areas (sides of the bay) and upwind flow in the deepest part (Winant, 2004). Similar mechanisms associated with spatial variations in forcing, such as those in the unstratified season, were expected to mold the flow during stratified conditions. However, the forcing was much weaker during this season and the stratification of the water column further dampened active forcing. Further investigations into the superinertial response of the bay during stratified conditions, with the same data sets, shall shed light into mechanisms that may in turn transfer energy and momentum to the subinertial field. For instance, Mode 1 exhibited low frequency modulations within which, a 13-day period or 0.074 cycles per day variability, could be caused by the interaction between sea breeze and diurnal $(\mathrm{O} 1)$ tide. 


\section{Conclusions}

Analysis of current velocity profiles measured at a cross-section in a semiarid bay of the Gulf of California during the stratified season revealed complex flow structures. A cyclonic recirculation observed during unstratified conditions persisted below the thermocline during the stratified season. Such recirculation is thought to be caused by a relatively flat bathymetry and the influence of advective accelerations. Above the thermocline, the flow moved downwind. Within the rich spectrum of variability in the flow structure observed, the dominant complex empirical orthogonal mode was vertically sheared for most part of the cross-section but explained only $\sim 33 \%$ of the variability observed. This mode of variation was related to water level slopes driven by wind forcing and exhibited low frequency modulations ( $<0.1$ cycles per day). The second mode explained only $20 \%$ and displayed a laterally sheared exchange flow structure. Other modes of variability had vertically and laterally sheared structures combined within the cross-section. These results present new challenges to the modeling of wind-driven stratified flows in semienclosed basins.

\section{References}

Caliskan, H., and A. Valle-Levinson, 2008: Wind-wave transformations in an elongated bay. Cont. Shelf Res., 28, 1702-1710.

Chen, S.N. and Sanford L.P., 2009. Lateral circulation driven by boundary mixing and the associated transport of sediments in idealized partially-mixed estuaries. Cont. Shelf Res., 29, 101-118, doi:10.1016/j.csr.2008.01.001.

Cheng, P., A. Valle-Levinson, C. D. Winant, A. Ponte, G. Gutierrez de Velasco and K. Winters, 2010. Upwelling-enhanced seasonal stratification in a semiarid bay. Continental Shelf Research, 30, 1241-1249.

Csanady, G. T., 1973: Wind-induced barotropic motions in long lakes.J. Phys. Oceanogr., 3, 429-438.

Emery, W. J., and R. E. Thomson, 2001: Data Analysis Methods in Physical Oceanography. 2nd ed. Elsevier, 638 pp.

Guo, X. and A. Valle-Levinson, 2008. Wind effects on the lateral structure of density-driven circulation in Chesapeake Bay, Cont. Shelf Res., 28, 2450-2471.

Hendershott, M. C. and A. Speranza, 1971. Co-oscillating tides 613 in long, narrow bays; the Taylor problem revisited. Deep Sea Res., 18, 959-980.

Henderson, F.M., 1966. Open Channel Flow. Mac Millan. 566 pp.

lanniello, J. P., 1977. Tidally induced residual currents in estuaries of constant breadth and depth, J. Mar. Res., 35, 755-786.

Large, W. G., and S. Pond, 1981: Open ocean momentum flux measurements in moderate to strong winds. J. Phys. Oceanogr., 11, 324-336.

Mathieu, P. P., E. Deleersnijder, B. Cushman-Roisin, J. M. Beckers, and K. Bolding, 2002. The role of topography in small wellmixed bays, with application to the lagoon of Mururoa. Cont. Shelf Res., 22, 1379-1395.

Morales, R. A. and G. Gutiérrez de Velasco, 1989. Mareas en el Golfo de California. Geofísica Internacional, 28, 25-46.

Officer, C.B., 1976. Physical Oceanography of Estuaries(and Associated Coastal Waters). John Wiley, New York, 465pp.

Ponte, A., G. Gutiérrez De Velasco, A. Valle-Levinson, K. Winters, and C. D. Winant, 2012. Wind-driven subinertial circulation inside a semi-enclosed bay in the Gulf of California. J. Phys. Oceanogr., 42, 940-955.

Sanay, R., Valle-Levinson, A., 2005. Wind-induced circulation in semienclosed homogeneous, rotating basins. J. Phys. Oceanogr. 35, 2520-2531. 
Valle-Levinson, A., 2011. Large Estuaries (Effects of Rotation). In: Wolanski E and McLusky DS (eds.) Treatise on Estuarine and Coastal Science, 2, 123-140. Waltham: Academic Press.

Winant, C.D., 2004. Three dimensional wind-driven flow in an elongated, rotating basin. J. Phys. Oceanogr. 34, 46.

Winant, C.D., 2011. A new method for separating surface gravity waves from ADCP measurements. Ph.D. Dissertation. University of Florida. 


\section{Figures}

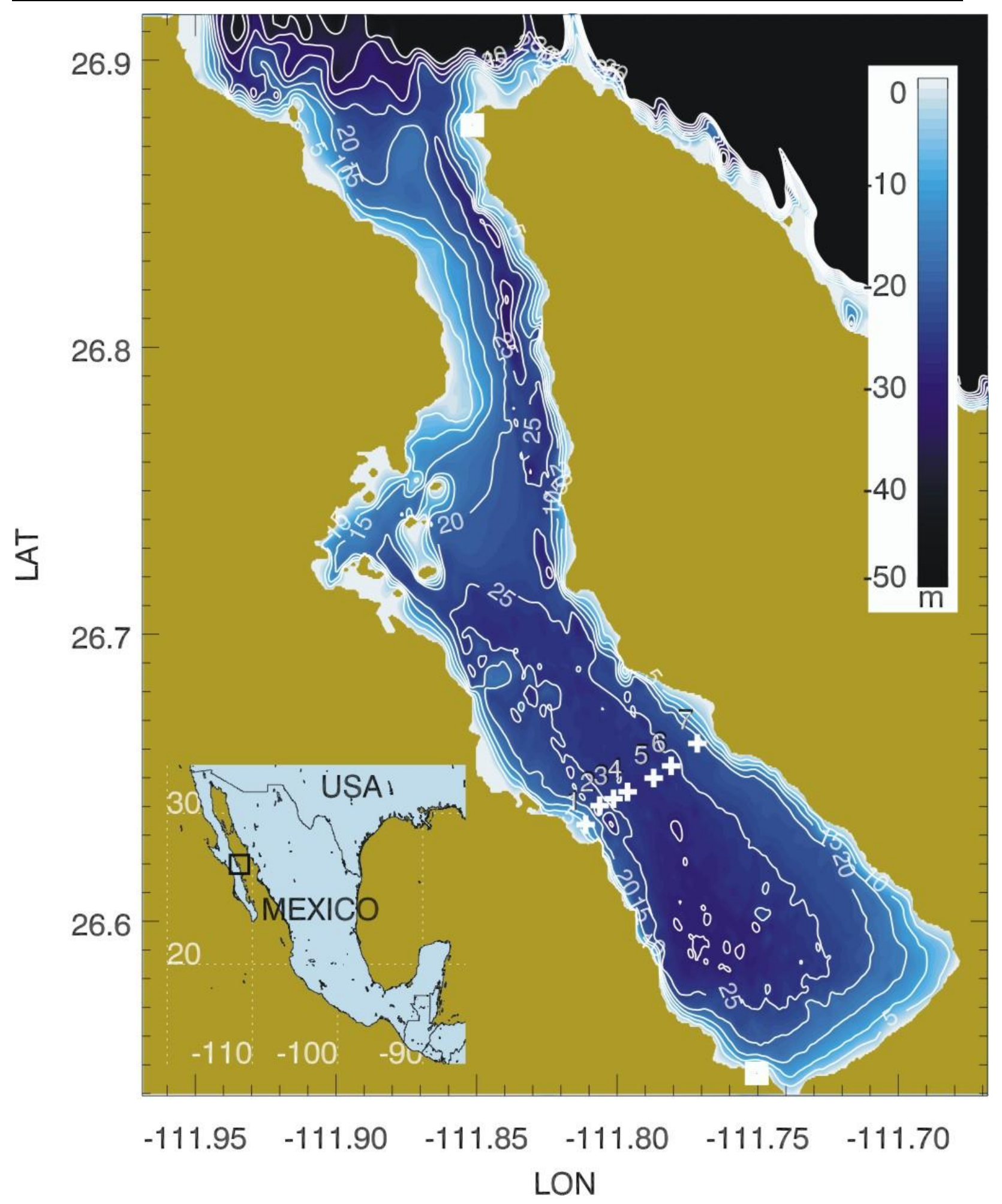

Figure 1. Chart of the study area, Bahia Concepcion in the Gulf of California, Mexico (square in the insert). Plus symbols indicate position of 7 moorings, labeled with their site number. White squares at both ends of the bay indicate location of pressure sensors and wind velocity measurements. Bathymetry is contoured every $5 \mathrm{~m}$. Colored contours follow the color bar to the side. 


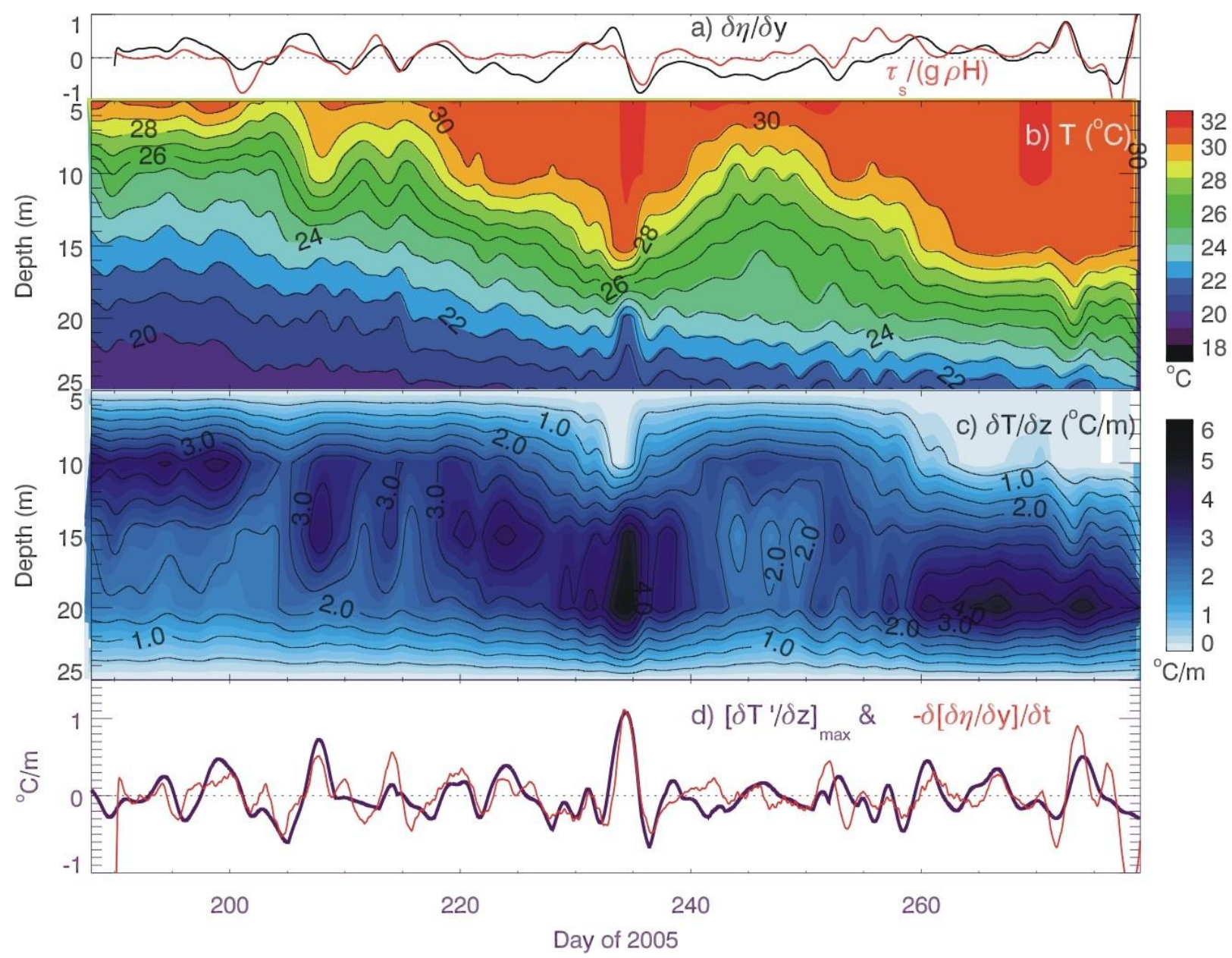

Figure 2. Records from water level, wind, and thermistors deployed at every $5 \mathrm{~m}$ depth in the middle of the sampling cross-section. a) Time series of water level slope between head and mouth of the bay $\left(\times 10^{-7}\right)$, as well as normalized wind stress at the bay mouth $\left(\times 10^{-7}\right)$. Positive slopes indicate water levels are higher at the mouth than at the head. Positive wind stress denotes northward wind. b) Time series of temperature profiles with a contour interval of $1^{\circ} \mathrm{C}$. c) Vertical gradient of temperature (absolute value contoured at intervals of $0.5^{\circ} \mathrm{C} / \mathrm{m}$ ). d) Deviations from a 10-day running mean of the maximum temperature gradient (thick line) and time rate of chanqe of water level slope $\left(\mathrm{s}^{-1}\right.$. multiplied times $-1 \times 10^{9}$ to match the scale). 


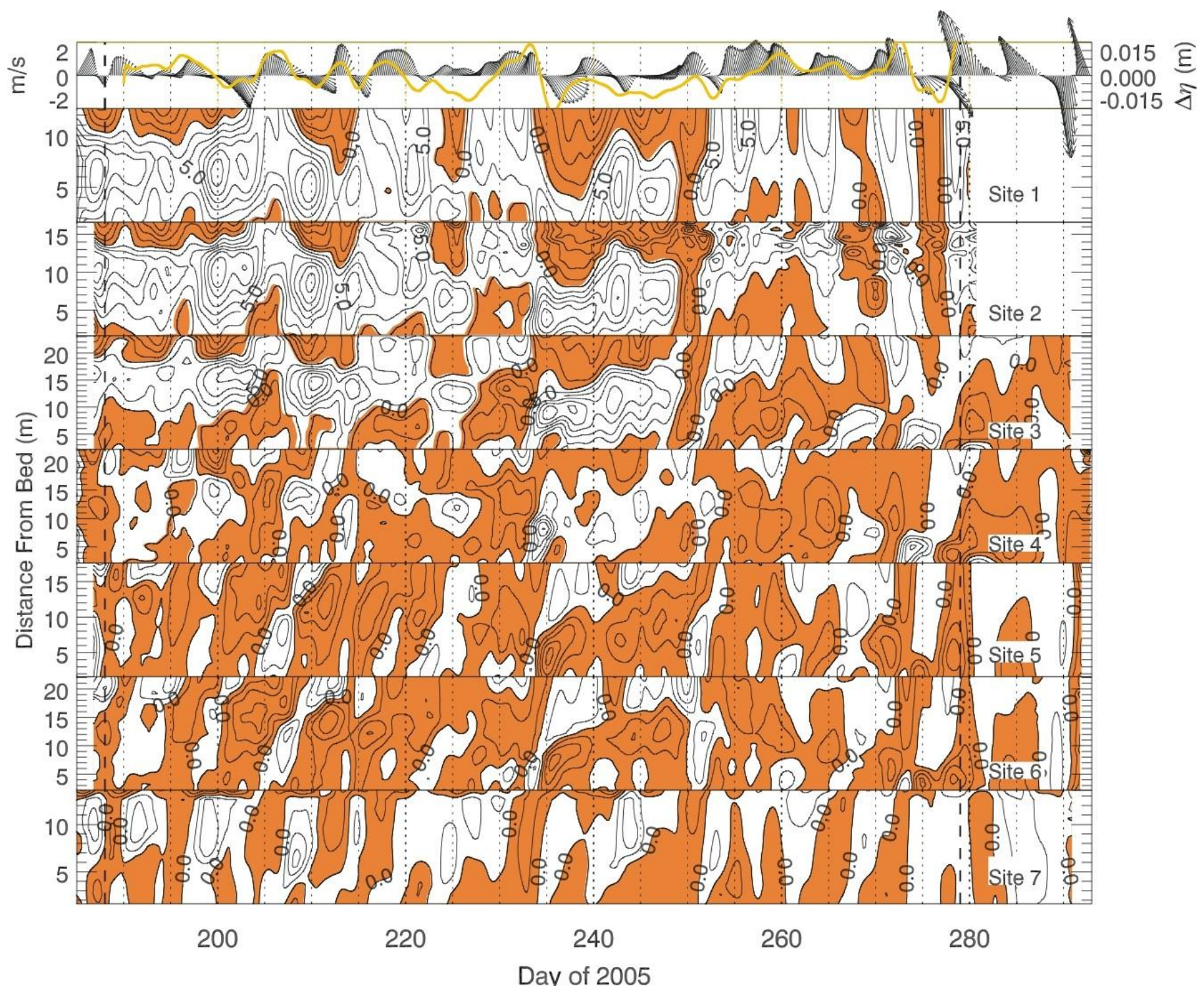

Figure 3. Time series of low-pass filtered wind velocity (showing direction toward which the wind blows) and water level difference between mouth and head of the bay (upper panel). Positive values denote higher elevation at the mouth. Subsequent panels show low-pass filtered profiles of principal-axis component of flow at each one of the seven sites going from west, at the top panel, to the east, at the bottom panel (see Fig. 1). Negative values (shaded in blue) indicate landward (toward the head of the bay) flow. Contour interval is $2.5 \mathrm{~cm} / \mathrm{s}$. Vertical, thick dashed lines limit the common period for which the CEOF analysis was done. 
a)
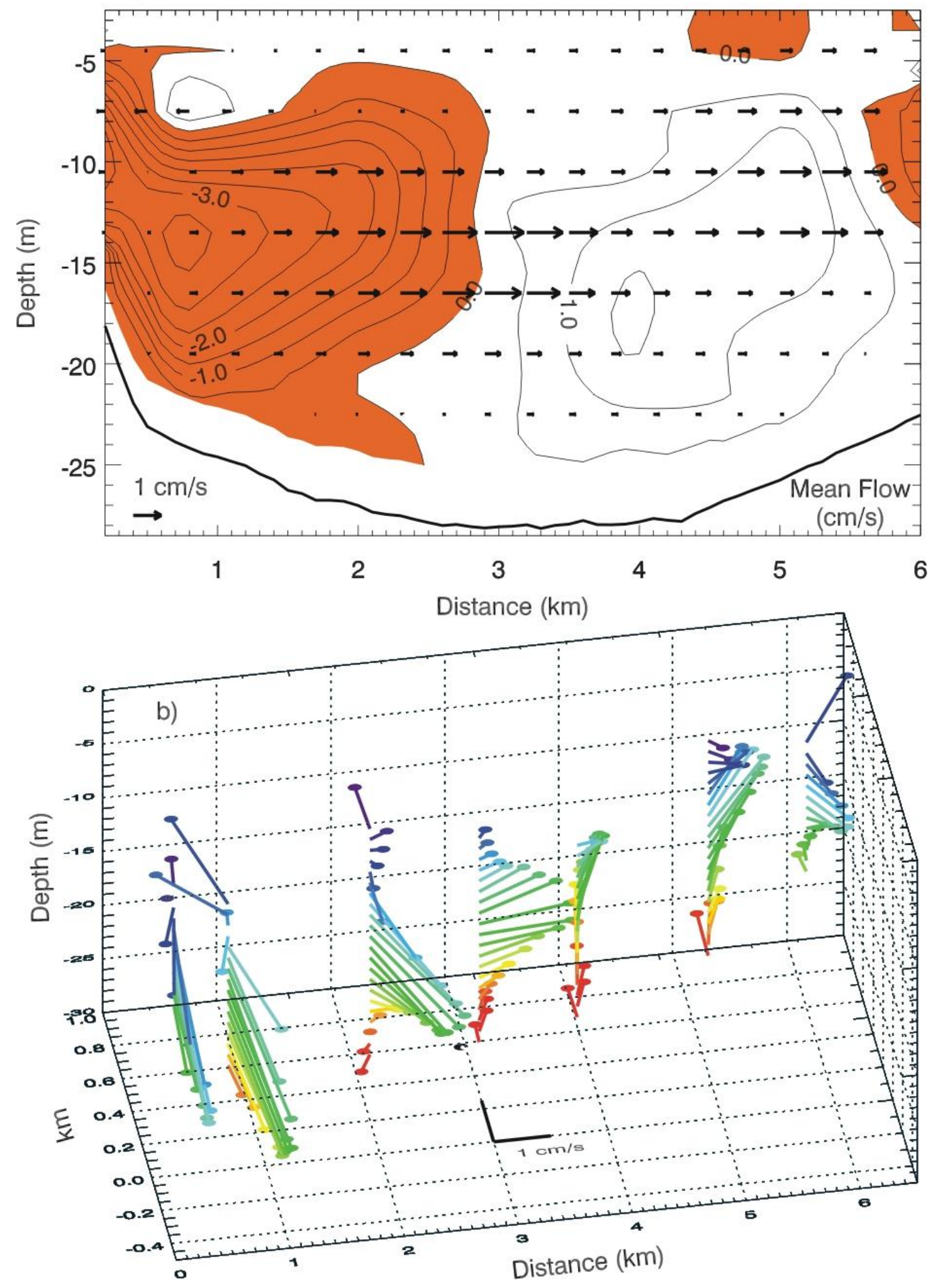

Figure 4. Mean flows $(\mathrm{cm} / \mathrm{s})$ throughout entire deployment, looking seaward. Orange-shaded contours indicate landward flows. Arrows denote cross-bay flows. Bottom panel displays a three-dimensional representation of the upper nanel 

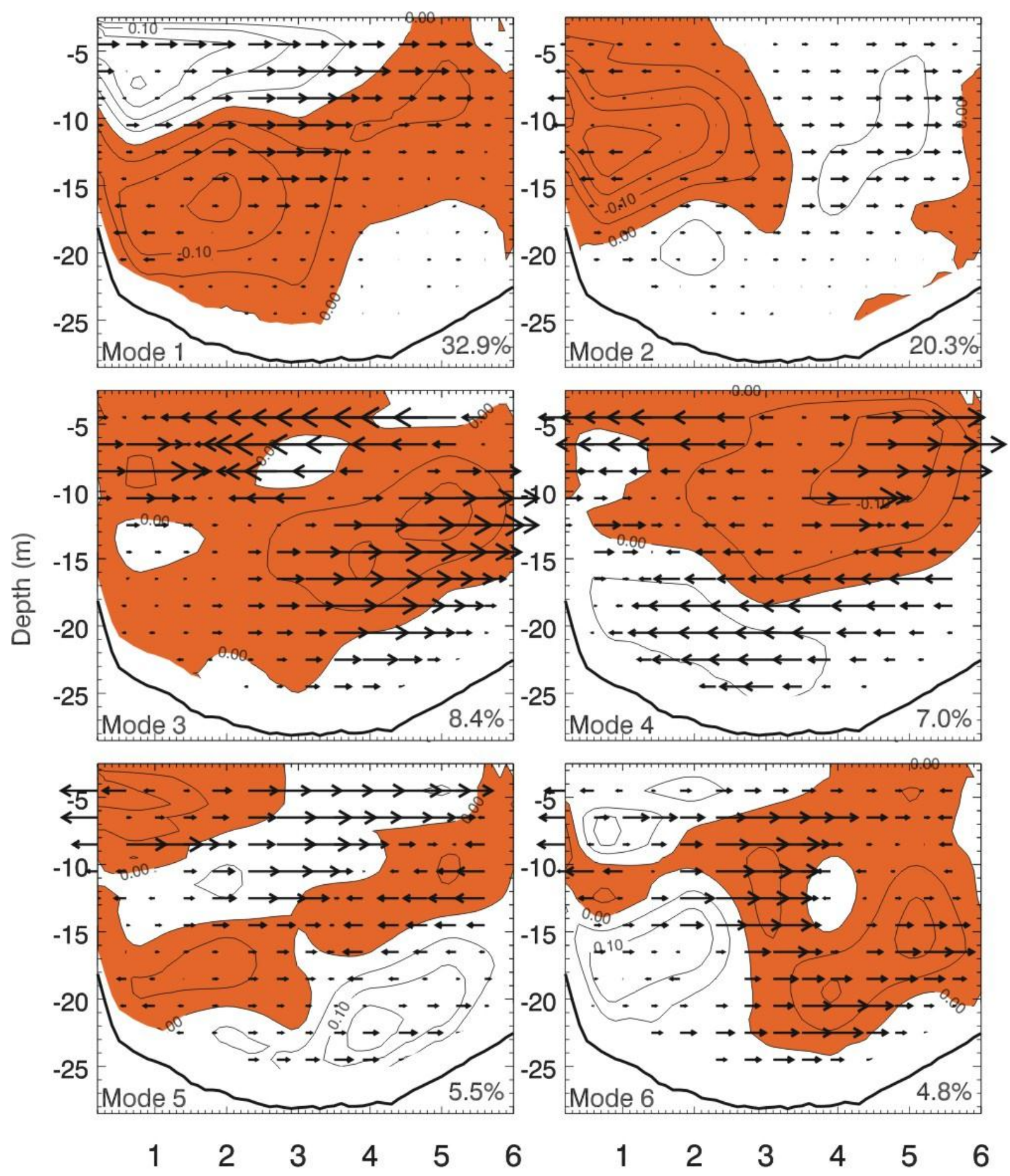

Distance (km)

Figure 5. Spatial structure of CEOF modes. Looking seaward. Contours indicate along-bay motion from the real part of the CEOF eigenvectors. Orange contours indicate landward motion when the coefficients of Figure 6 are positive. Arrows denote lateral flows represented by the imaginary part of the CEOF eigenvectors. Lateral flows show essentially recirculating features in the transect. 


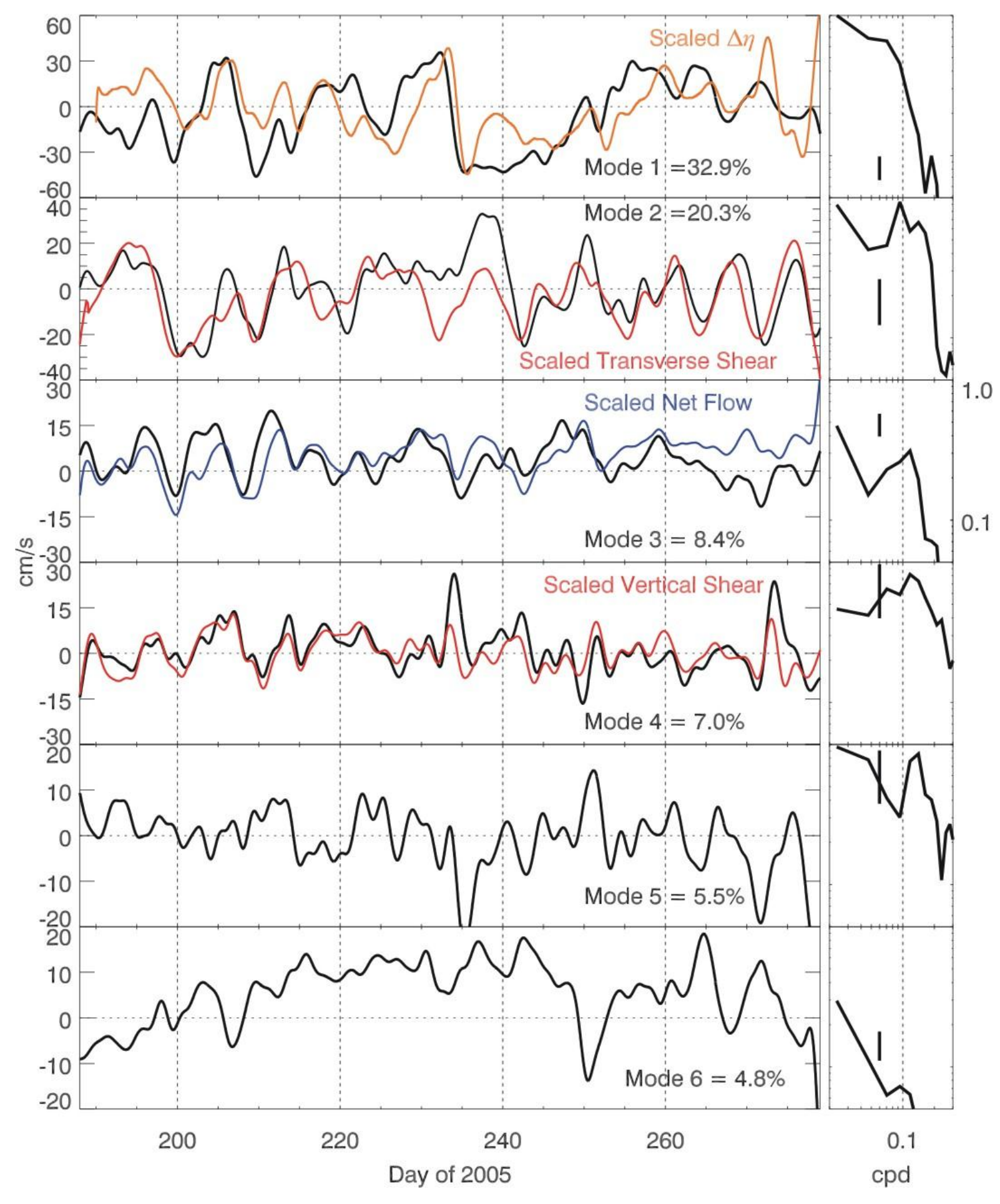

Figure 6. Time series of each CEOF coefficient (real part, related to along-bay flows) and spectra illustrating the variability of each coefficient time series. The upper 4 panels also show scaled versions of possible forcing agents. For mode $1, \Delta \eta$ is multiplied times 5500 . For mode 2, the transverse velocity difference between westernmost and easternmost sites (in $\mathrm{cm} / \mathrm{s}$ ) is multiplied times 4 . For mode 3 , the flow sectional mean $(\mathrm{cm} / \mathrm{s}$ ) is multiplied times 10 . For mode 4 , the top to bottom velocity difference $(\mathrm{cm} / \mathrm{s})$ at the deepest site is multiplied times -1.5 . 